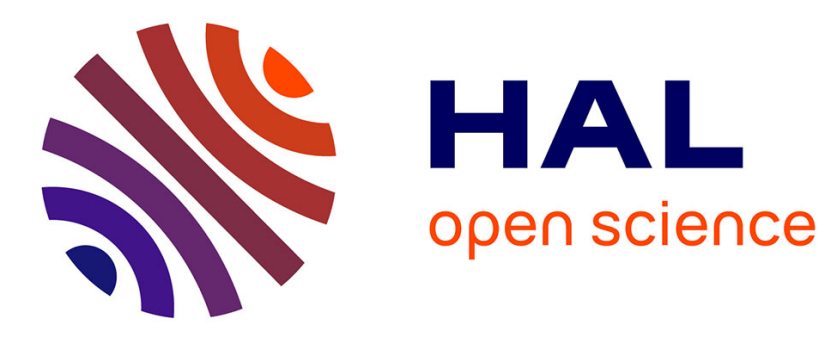

\title{
Ultra-Compact and High-Efficiency Rectenna for Wireless Sensing Applications in Concrete Structure
}

Alassane Sidibe, Alexandru Takacs, Gael Loubet, Daniela Dragomirescu

\section{To cite this version:}

Alassane Sidibe, Alexandru Takacs, Gael Loubet, Daniela Dragomirescu. Ultra-Compact and HighEfficiency Rectenna for Wireless Sensing Applications in Concrete Structure. 2020 IEEE/MTT-S International Microwave Symposium (IMS), Aug 2020, Los Angeles, United States. pp.988-991, 10.1109/IMS30576.2020.9223813 . hal-03014084

\author{
HAL Id: hal-03014084 \\ https://hal.laas.fr/hal-03014084
}

Submitted on 3 Dec 2020

HAL is a multi-disciplinary open access archive for the deposit and dissemination of scientific research documents, whether they are published or not. The documents may come from teaching and research institutions in France or abroad, or from public or private research centers.
L'archive ouverte pluridisciplinaire HAL, est destinée au dépôt et à la diffusion de documents scientifiques de niveau recherche, publiés ou non, émanant des établissements d'enseignement et de recherche français ou étrangers, des laboratoires publics ou privés. 


\section{Ultra-Compact and High-Efficiency Rectenna for Wireless Sensing Applications in Concrete Structure}

\author{
Alassane Sidibe \\ LAAS-CNRS \\ Université de Toulouse, \\ CNRS \\ Toulouse, France \\ asidibe@laas.fr
}

\author{
Alexandru Takacs \\ LAAS-CNRS, UPS \\ Université de Toulouse, \\ CNRS \\ Toulouse, France \\ atakacs@laas.fr
}

\author{
Gaël Loubet \\ LAAS-CNRS \\ Université de Toulouse, \\ CNRS \\ Toulouse, France \\ gael.loubet@laas.fr
}

\author{
Daniela Dragomirescu \\ LAAS-CNRS, INSA \\ Université de Toulouse, \\ CNRS \\ Toulouse, France \\ daniela@laas.fr
}

\begin{abstract}
This paper presents an ultra-compact and high efficiency rectenna which can power wireless sensing nodes fully embedded in a concre te structure. The innovative proposed design is optimized in term of efficiency and compactness for the targeted application. The rectenna is compact, which a volume of $56 \mathrm{~mm} x$ $32 \mathrm{~mm} \times 10 \mathrm{~mm},\left(0.0004 \lambda^{3}\right)$ and can reach a maximum RF to dc conversion efficiency of $70 \%$ at $868 \mathrm{MHz}$ for $10 \mathrm{k} \Omega$ load and for an illuminating RF power density of $4 \mu \mathrm{W} / \mathrm{cm}^{2}$. The use of a metallic cavity increases the rectennaperformances and limits the negative impact of the concre te material. Thus, the rectenna into the cavity harvest a dc voltage up to $1.15 \mathrm{~V}$ when the rectenna is illuminated with a RF power density of $1 \mu \mathrm{W} / \mathrm{cm}^{2}$. Experimental results of the rectenna embedded in the concre te beam confirms the feasibility of powe ring a wire less sensor by wireless power transmission.
\end{abstract}

Keywords-Rectenna, wireless power transmission, energy harvesting, wireless sensing application, structural health monitoring, concrete.

\section{INTRODUCTION}

The use of Radiofrequency (RF) Energy Harvesting (EH) or alternatively of the RF Wireless Power Transmission (WPT) are not now well considered in harsh environments.

The work presented in [1] addresses an original concept of wireless smart-node network (WSN) for Structural Health Monitoring (SHM) applications. Researchers also evaluate the potential of RFID technology in concrete structure. Similarly, a concrete quality sensor based on chipless ultra-wideband (UWB) radio frequency identification (RFID) is presented in [2]. In [3], a RFID sensor system was developed for being embedded into concrete structures.

However, several challenges must be investigated as the lifetime of the nodes once embedded and the long-term communication reliability.

To overcome the lifetime challenges, we propose in this paper a unique design of an improved Wireless Power Interface embedded in a concrete structure working in the $868 \mathrm{MHz}$ Industrial, Scientific and Medical (ISM) frequency band. The Wireless Power Interface commonly called a Rectenna (Rectifying antenna) was developed in order to supply a Power Management Unit (PMU) by WPT or EH.
Additionally, a metallic cavity was designed in order to minimize the losses which appears once the rectenna is embedded in the concrete. The two prototypes (rectenna with and without cavity) were tested and presented in section III. Experimental test of the rectenna in the concrete is highlighted in section IV.

\section{Rectenna Design and Measurement}

The proposed rectenna consists of a differential rectifier directly connected to a dipole antenna designed for a $50 \Omega$ input impedance. Next, the entire design was embedded in a metallic cavity in order to increase the harvested dc voltage. We proposed a compact $3 \mathrm{D}$ rectenna with a high $\mathrm{RF}$ to dc conversion efficiency.

\section{A. Antenna design}

A compact antenna was designed and simulated thanks to HFSS software for the targeted application. It is like a RFID dipole antenna with a short-circuited loop as presented in Fig. 1 (a). By adding two capacitive arms, it is possible to form a 3D configuration of the antenna and reduce its size. The dipole was connected to the metallic arms by an electric line. Its position was chosen to tune the resonant frequency of the antenna. Two antennas with different electrical line positions were manufactured namely: DPLC5 (Fig. 1 (b)) and DPLC3 (Fig. 1 (c)). The antennas were manufactured on FR4 substrate (with a thickness of $0.8 \mathrm{~mm}$ ). Due to the planar configuration of the dipole, an easy way to characterize the antenna was to add a 50 $\Omega$ UFL connector. As presented in Fig. 3 (a), a frequency shift of $40 \mathrm{MHz}$ (i.e. $4.75 \%$ ) between simulation and measurement was observed for DPLC3 and DPLC5. This frequency shift is mainly due to the manual assembling/connecting of the vertical arms. For the final implementation of the rectenna, DPLC5 configuration was chosen.

In the literature, some research presents the investigation of antenna embedded in concrete. A microstrip patch antenna operating at $2.5 \mathrm{GHz}$ was designed for civil engineering applications [4]. Otherwise in [5] is presented a design of the UHF RFID tag antenna suitable for embedded use in a concrete floor. This antenna consists of a ceramic path, a parasitic patch and a metal cavity which improve the gain. 


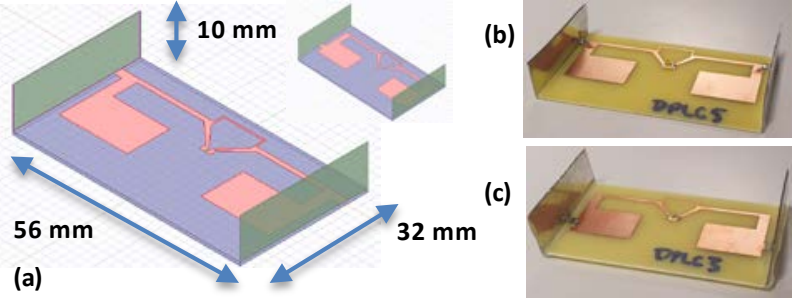

Figure 1: Simulation design on HFSS Software (a) and photo of the fabricated antenna DPLC3 and DPLC5.

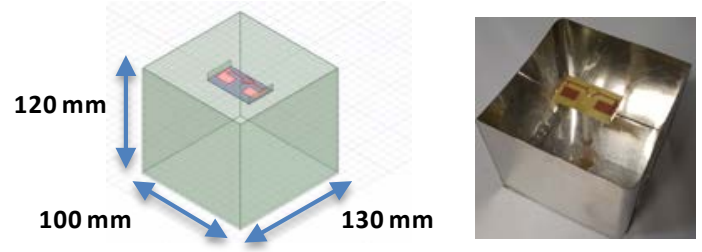

Figure 2: Simulation design and photo of the manufactured prototype of DPL5 embedded in a metallic cavity.
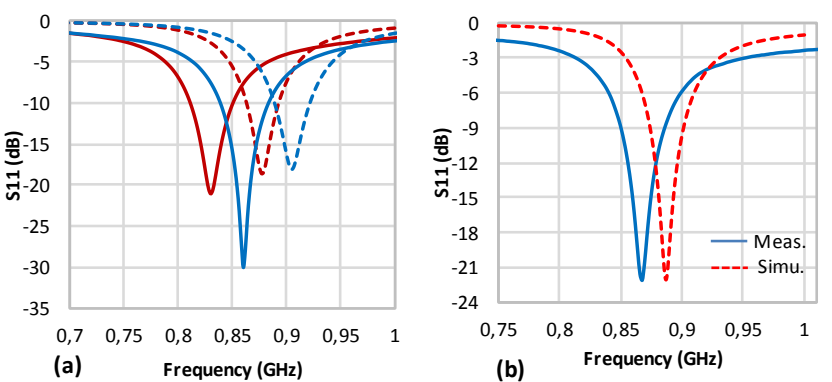

Figure 3 : (a) Measured (continuous line) and simulated (dashed line) of the return loss (S11) for DPLC3 (red line) and DPLC5 (blue line). (b) Simulated (red dashed line) and measurement (blue continuous line) of the return loss (S11) of the antenna DPLC5 embedded in the metallic cavity.

Consequently, to minimize the impact of the high dielectric constant and high dielectric losses of the concrete material on the antenna/rectenna performances, we proposed to add a top open metallic cavity which covers the antenna (Fig. 2). Its size and the antenna location from the bottom side were optimized in order to increase the antenna gain and to avoid antenna detuning into the concrete. For this implementation, we considered the frequency shift of the antenna as mentioned before. The antenna is placed at $10 \mathrm{~cm}$ from the bottom of cavity and the metallic arms was also tune at $7.5 \mathrm{~mm}$. Fig. 3 (b) plots the return loss (S11) of the antenna inside the manufactured cavity.

The radiation pattern of the manufactured antenna was measured in an anechoic chamber. The measured and simulated gain in the E-plane (that is a vertical cut plane orthogonal to the antenna horizontal plane) obtained for the DPLC5 antenna with and without metallic cavity are represented in Fig. 4. The maximum measured gain obtained with DPCL5 antenna is +1.7 $\mathrm{dBi}$. By adding the metallic cavity, the gain is multiplied by 2.5 reaching up to $+4.5 \mathrm{dBi}$.

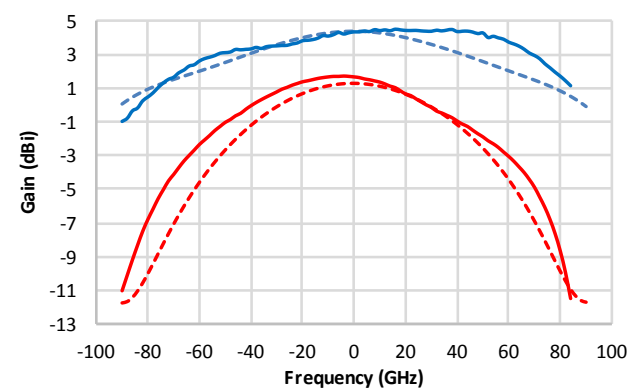

Figure 4: Radiation pattern (gain in $\mathrm{dB}$ ) at $868 \mathrm{MHz}$ in the E-plane: experimental (continuous line) and simulation (dashed line) results for the DPLC5 antenna in the metallic cavity (blue line) and DPLC5 antenna only (red line).

\section{B. Full Wave Rectifier Design}

This section presents the rectifier design optimized to operate at low power densities. Several configurations of rectifiers exist. The proposed design (in Fig. 5) is a doubler rectifier composed by SMS7630_005LF Schottky Diode from Skyworks investigated at low power level. The size considerations allow us to choose a lumped LC (33 $\mathrm{nH}$ and 4 $\mathrm{pF})$ matching network. The simulation was done in ADS Software and the circuit was built on FR-4 substrate with a thickness of $0.8 \mathrm{~mm}$. Fig. 6 shows a photo of the manufactured rectifier and its return loss for different input power.

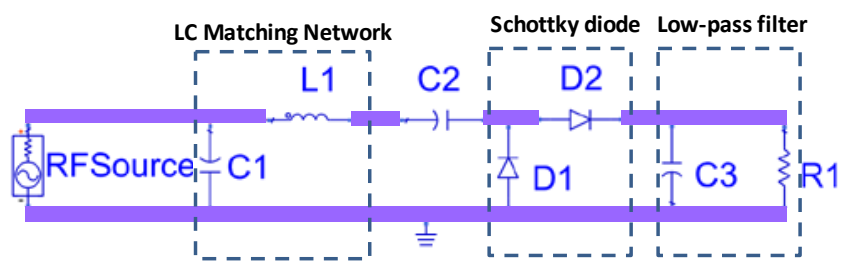

Figure 5: Schematic of the doubler rectifier.

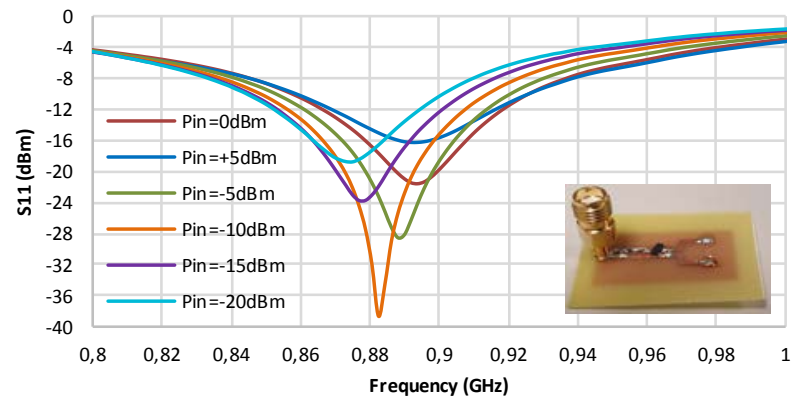

Figure 6: Measured return loss of the rectifier for different RF input power. The inset shows a photo of the manufactured prototype.

The maximal measured RF to dc conversion efficiency and dc voltage of the rectifier is about $35 \%$ and $330 \mathrm{mV}$ for a dc load of $10 \mathrm{k} \Omega$ load at $870 \mathrm{MHz}$ with an input power of $-15 \mathrm{dBm}$. The load value was chosen in order to emulate the input impedance of the PMU for the wireless sensors. This one is not the optimal load impedance of the rectifier.

\section{IMPLEMENTED RECTENNA}

The final design consists to connect the antenna with the rectifier to form the rectenna as previously presented. Two 
prototypes were tested, the rectenna without cavity named RT and the rectenna placed in the metallic cavity named RMC. The experimental setup was placed inside an anechoic chamber. It consists on illuminating the rectenna under test positioned at a Far Field region of transmitter with linear Polarization E-Field. The transmitting Patch antenna is connected to an Anritsu MG3694B power generator (placed outside) though a coaxial cable. The harvested dc voltage across a $10 \mathrm{k} \Omega$ load is measured by using a Multimeter. The following expression in (1) was used to calculate RF to dc conversion efficiency $\eta$ :

$$
\eta=100 \cdot \frac{P_{D C}}{P_{R F}}=\frac{P_{D C}}{S \cdot A_{e f f}} \frac{4 \cdot \pi \cdot P_{D C}}{S \cdot G_{r} \cdot \lambda^{2}} \text { and } S=\frac{P_{t} \cdot G_{t}}{d^{2} \cdot 4 \cdot \pi}
$$

where $P_{D C}$ is the harvested dc power measured across the load and $S$ is the incident EM power density illuminating the rectenna. $A_{e f f}$ is the antenna effective area computed thanks to the gain of DPLC5 with or without cavity $\left(G_{r}\right)$ and the wavelength $(\lambda) . P_{t}$ is the RF power injected to the patch antenna (Gain $G_{t}$ ) positioned at a distance $d$ of 1.5 meter from the rectenna.

For accurate measurement, the insertion losses through the RF cable used to connect the RF source to the transmitting (Tx) antenna (about $3 \mathrm{~dB}$ ) was measured with a power meter and subtracted from the patch antenna gain (about $9.6 \mathrm{dBi}$ ). The measured dc voltage of the rectenna as function of frequency is presented in Fig. 7. The resulting dc voltage and the efficiency (at $868 \mathrm{MHz}$ ) as function of the illuminating RF power density are presented in Fig. 8. We observe that for higher power density level, RT is more efficient than RMC and reach a maximum efficiency of $70 \%$. However, RMC maintains a good efficiency (65\% max).

For a power density of $1 \mu \mathrm{W} / \mathrm{cm}^{2}$, the harvested dc voltage is $1300 \mathrm{mV}$ and $900 \mathrm{mV}$ respectively for the rectenna with (RMC) and without the cavity (RT).

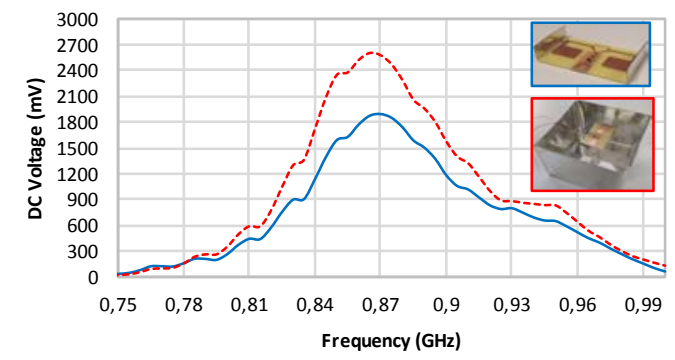

Figure 7: Measured dc voltage for the two manufactured rectennas as function of the frequency in an anechoic chamber. RMC (red dashed line) and RT (continuous blue line) at a power density of $3.4 \mu \mathrm{W} / \mathrm{cm}^{2}$.

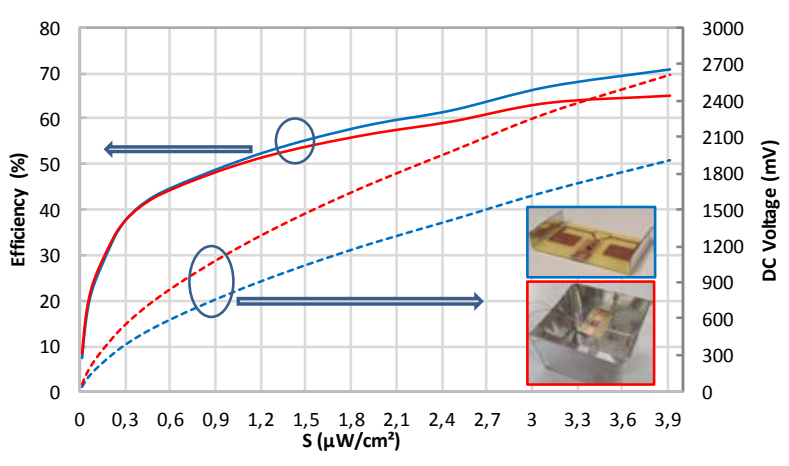

Figure 8: Measured RF to dc conversion efficiency (continuous line) and dc voltage (dashed line) as function of the illuminating power densities at $868 \mathrm{MHz}$. RT (blue line) and RMC (red line).

\section{EXPERIMENTAL RESULTS WITH THE CONCRETE BEAM}

In order to perform experimentations in the targeted harsh environment, a reinforced concrete beam (size: $135 \mathrm{~cm}$ by 35 $\mathrm{cm}$ by $35 \mathrm{~cm}$ ) was designed and manufactured. The experimental setup consists of illuminating the rectenna embedded in the concrete structure with a linearly polarized EField as shown in Fig. 9. The RF power transmitter is an Anritsu MG3694B generator connected to a patch antenna though a coaxial cable. The obtained dc voltage was measured by using a dc multimeter. During the measurement, the antenna was placed on the roof at $156 \mathrm{~cm}$ of the concrete beam (upper side). Otherwise, the rectenna in the concrete cavity was placed in order to match the polarization of the transmitting antenna. The transmitting patch antenna has a gain of $+9 \mathrm{dBi}$.

Fig. 10 shows the harvested dc power obtained inside the concrete structure for the RT and the RMC as function of the Effective Isotropic Radiated Power (EIRP).

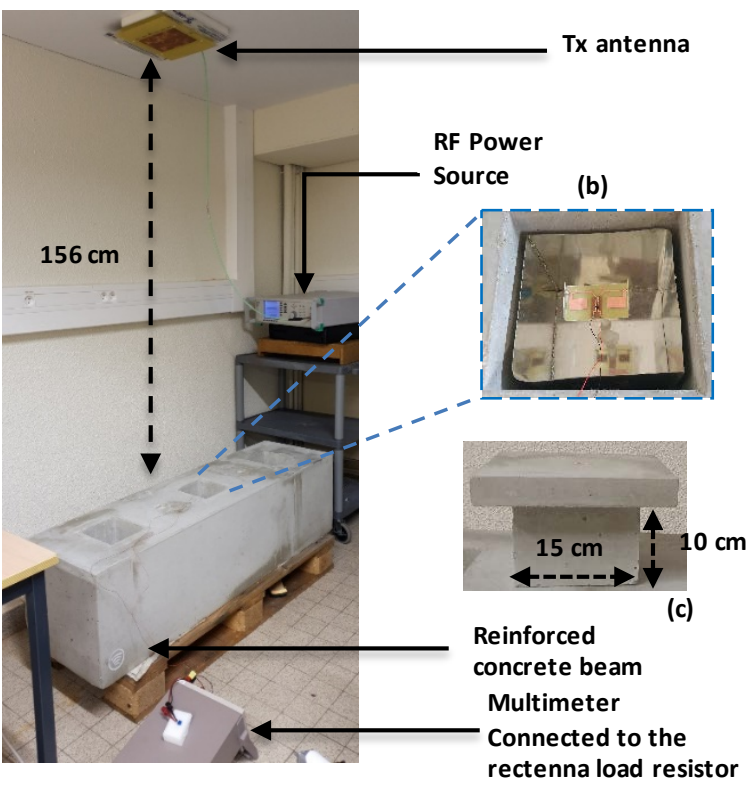

Figure 9: (a) Experimental setup of rectenna inside concrete,(b) RMC with its metallic cavity embedded in the concrete. (c) The cover of the concrete beam. 
The total distance between the transmitting antenna and the rectenna is $170 \mathrm{~cm}$ (with the height of the concrete cover). Uncovered measurement corresponds to the rectenna placed in the concrete without any concrete cover on the top. RT results was obtained with covered concrete at different height positions from the bottom of the concrete cavity.

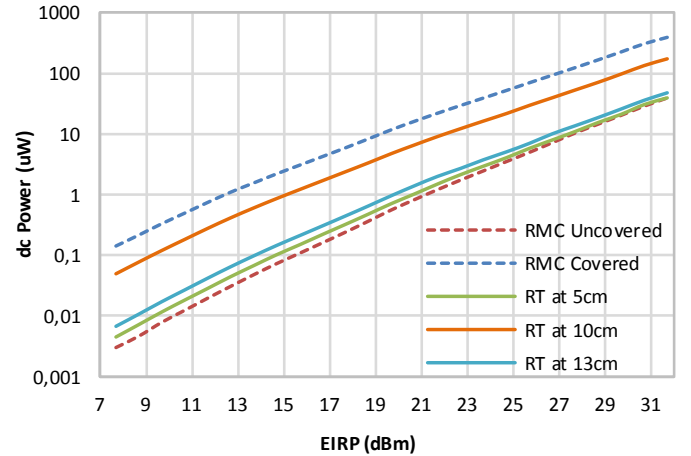

Figure 10: Harvested dc power of the RMC and the RT as function of the EIRP of the RF source positioned at $156 \mathrm{~cm}$ far away from the top of the concrete beam. RT was fully embedded in the concrete cavity with the cover and positioned at different height from the bottom of cavity.

Table 1. Performances comparis on of the fabricated rectenna with the state of the art.

\begin{tabular}{|c|c|c|c|c|c|c|c|c|}
\hline References & $\begin{array}{l}\text { Freq. } \\
\text { (GHz) }\end{array}$ & Diode & $\begin{array}{c}\text { Input Power } \\
\text { (dBm) /EIRP } \\
(\mathrm{dBm})\end{array}$ & $\begin{array}{c}\mathrm{S} \\
\left(\mu \mathrm{W} / \mathrm{cm}^{2}\right)\end{array}$ & $\begin{array}{l}\text { Eff. } \\
\text { (\%) }\end{array}$ & G(dBi) & $\begin{array}{c}\text { Rectenna size } \\
(\mathrm{mm} \times \mathrm{mm} \times \mathbf{~ m m})\end{array}$ & $\begin{array}{c}\text { dc } \\
\text { Power } \\
(\mu W) \\
\end{array}$ \\
\hline [6] & 0.868 & HSMS285C & -- & 0.1 & 30.2 & 6.43 & $\mathrm{NR}^{*}$ & 12.62 \\
\hline$[8]$ & 0.9 & HSMS2850 & -- & 1 & 40 & 1.3 & $110 \times 110\left(0.11 \lambda^{2}\right)$ & 47.7 \\
\hline [9] & $\begin{array}{l}1.96 \\
2.45 \\
\end{array}$ & $\begin{array}{l}\text { SMS7630 } \\
\text { SMS7621 }\end{array}$ & -- & 200 & 54.2 & NR & $60 \times 75\left(0.19 \lambda^{2}\right)$ & 4200 \\
\hline $\begin{array}{c}\text { This work } \\
\text { In anechoic chamber } \\
\text { RT } \\
\text { RMC } \\
\text { In Concrete structure } \\
\text { RT (height }=10 \mathrm{~cm} \text { ) } \\
\text { RMC }\end{array}$ & 0.868 & $\begin{array}{c}\text { SMS7630 } \\
\text { 005LF }\end{array}$ & $\begin{array}{c}-- \\
--/ 23.7 \\
--/ 23.7\end{array}$ & $\begin{array}{l}1 \\
1 \\
1 \\
1\end{array}$ & $\begin{array}{c}52.74 \% \\
51.7 \% \\
-- \\
--\end{array}$ & $\begin{array}{l}1.7 \\
4.5 \\
\\
1.7 \\
4.5\end{array}$ & $\begin{array}{c}52 \times 32 \times 10\left(0.0004 \lambda^{3}\right) \\
130 \times 130 \times 120 \\
52 \times 32 \times 10\left(0.0004 \lambda^{3}\right) \\
130 \times 130 \times 120\end{array}$ & $\begin{array}{c}85.7 \\
171 \\
\\
16.22 \\
38.84\end{array}$ \\
\hline
\end{tabular}

It is obvious that the concrete cavity acts as dielectric resonant cavity and the rectenna position should be optimized inside this cavity. The best results were obtained with RMC positioned inside the covered cavity in the concrete because a dual resonance occurs: (i) first resonance inside the top-open metallic cavity, (ii) the second one in the top-covered concrete cavity. So that, the influence of the concrete material can be reduced by: (i) choosing the appropriate dimensions of the hole in the concrete (it was not possible in our case because the concrete beam was manufactured before the experiments), (ii) inserting the rectenna in a top-open metallic cavity (iii) controlling and optimizing the rectenna position inside the metallic cavity (when used) or in the concrete cavity (when used standalone). An optimization methodology/algorithm by using intensive electromagnetic simulations is under development in order to find the best-fitted size of the concrete and metallic cavity and the optimal position of the rectenna. More results will be available at conference.

\section{CONCLUSION}

In this paper we present a unique and ultra-compact design of rectenna $\left(0.0004 \lambda^{3}\right.$ at $\left.868 \mathrm{MHz}\right)$ dedicated to $\mathrm{RF}$ wireless power transmission in concrete structures. It consists of a doubler rectifier using two SMS7650-005LF Schottky diodes and a 3D compact antenna. The prototypes were fabricated and characterized in anechoic chamber. The 3D compact antenna (DPLC5) of our rectenna exhibits a gain of $1.7 \mathrm{dBi}$ (when measured standalone) and $4.5 \mathrm{dBi}$ when inserted in metallic cavity. The measured rectenna conversion efficiency is about $54 \%$ for an illuminating power density of $1.5 \mu \mathrm{W} / \mathrm{cm}^{2}$ and $10 \mathrm{k} \Omega$ load. Therefore, additional measurements of the rectenna embedded in the concrete structure were performed. With an EIRP of $23.7 \mathrm{dBm}$, the harvested dc voltage is about $623 \mathrm{mV}$ and $402 \mathrm{mV}$ for RMC and RT (positioned at $13 \mathrm{~cm}$ from the bottom), respectively.

As compared with the state-of-the-art designs reported in table I, the proposed rectenna is ultra-compact and exhibits excellent performances. The experimental results confirm that the proposed rectenna can be used for wirelessly. 


\section{REFERENCES}

[1] G. Loubet, A. Takacs, D. Dragomirescu, "Towards the design of wireless Communication Reinforced Concrete”, IEEE Access Special Section on Wirelessly Powered Networks: Algorithms Applications and Technologies, vol. 6, pp. 1-13, 2018.

[2] A. Ramos, D. Girbau, A. Lazaro and R. Villarino, "Wireless Concrete Mixture Composition Sensor Based on Time-Coded UWB RFID”, IEEE Microwave and Wireless Access Components Letters, vol. 25, no. 10, Oct. 2015.

[3] M. Bartholmai, S. Johann, M. Kammermeier, M. Mueller, C. Strangfleld, "Transmission Characteristics of RFID Sensor Systems Embedded in Concrete” IEEE Sensors, Nov. 2016.

[4] G. Roqueto, S. Irteza, J. Romeu and L. Jofre, “A Novel Compact UHF Wideband Antenna for Near Field Electrical Characterization of Steel Fiber Reinforced Concrete,” IEEE Sensor Journal, vol. 7, no 12, Dec.

[5] S-H Jeong and H-W Son, "UHF RFID Tag Antenna for Embedded Use in a Concrete Floor," IEEE Antennas and Wireless Propagation Letters, vol. 10, 2011.

[6] S. D. Assimonis, S. N. Daskalakis, and A. Bletsas, "Sensitive and Efficient RF Harvesting Supply for Batteryless Backscatter Sensor Networks,” IEEE Trans. Microw. Theory Techn., vol. 64, no. 4, pp. 1327-1338, Apr. 2016.

[7] A. Sidibe, A Takacs, A. Okba, H. Aubert, "Design and Characterization of a Compact Rectenna for Structural Health Monitoring Applications”, IEEE International Symposium on Antennas and Propagation and USNC-URSI Radio Science Meeting, vol. 6, pp. 2, July 2019.

[8] V. Palazzi, J. Hester, J. Bito, F. Alimenti, C. Kalialakis, A. Collado, P. Mezzanotte, A. Georgiadis, L. Roselli, M.M. Tentzeris, "A Novel UltraLightweight Multiband Rectenna on Paper for RF Energy Harvesting in the Next Generation LTE Bands," IEEE Trans. Microw. Theory Techn., vol. 66, no. 1, pp. 366-379, Jan. 2018.

[9] E. Falkenstein, M. Roberg, and Z. Popovic, "Low-Power Wireless Power Delivery,” IEEE Trans. Microw. Theory Techn., vol. 60, no. 7, pp. 2277-2286, Jul. 2012

[10] K. Niotaki, S. Kim, S. Jeong, A. Collado, A. Georgiadis, and M. M. Tentzeris, “A Compact Dual-Band Rectenna Using Slot-Loaded Dual Band Folded Dipole Antenna,” IEEE Antennas Wirel. Propag. Lett., vol. 12, pp. 1634-1637, 2013.

[11] K. M. Z. Shams and M. Ali, "Wireless Power Transmission to a Buried Sensor in Concrete,” IEEE Sensor Journal, vol. 7, no 12, Dec. 